\title{
Thresholds Power Profiles Predict Performance in Youth Road Cycling
}

\section{Gabriele Gallo, Luca Filipas, Michele Tornaghi, Mattia Garbin, Roberto Codella, Nicola Lovecchio, and Daniele Zaccaria}

\begin{abstract}
Purpose: To analyze the anthropometric and physiological characteristics of competitive 15- to 16-year-old young male road cyclists and scale them according to a dichotomous category of successful/unsuccessful riders. Methods: A total of 103 15- to 16-year-old male road cyclists competing in the Italian national under 17 category performed a laboratory incremental exercise test during the in-season period. Age, height, body mass, body mass index, peak height velocity, and absolute and relative power output at $2 \mathrm{mmol} / \mathrm{L}$ and $4 \mathrm{mmol} / \mathrm{L}$ of blood lactate concentration were compared between 2 subgroups, including those scoring at least 1 point (successful, $\mathrm{n}=70$ ) and those that did not score points (unsuccessful, $\mathrm{n}=61$ ) in the general season ranking. Results: Successful and unsuccessful riders did not differ anthropometrically. Successful riders recorded significantly higher absolute and relative power output at $2 \mathrm{mmol} / \mathrm{L}$ and $4 \mathrm{mmol} / \mathrm{L}$ of blood lactate concentration compared with unsuccessful riders. Successful riders were also significantly older and had advanced biological maturation compared with their unsuccessful counterparts. Conclusion: Power associated with blood lactate profiles, together with chronological age and peak height velocity, plays an important role in determining race results in under 17 road cycling. Physiological tests could be helpful for coaches to measure these performance predictors.
\end{abstract}

Keywords: youth cycling, blood lactate, power output, race results, PHV

International road cycling categories ruled by the Union Cycliste Internationale provides 3 age-limited categories that have an international calendar culminating with World Championships: junior 17-18 y), under 23 (19-23 y), and elite (>23 y). Under the age f 17 , youth cycling categories are regulated only at a national level. Although called by a different name depending on the national federation ("Allievi," Italy; "Cadet," France; "Cadete," Spain; "Niuwelingen," Holland; "Debutantes," Belgium; "Youth A," Great Britain), the age category prior to "junior" is almost always biannual including athletes aged 15 and 16 years. To the best of our knowledge, unlike junior, ${ }^{1,2}$ under $23^{1,3,4}$ and elite, ${ }^{1,5}$ no anthropometric or physiological data of 15- to 16-year-old competitive cyclists were corted in previous studies.

Physiological factors such as maximal oxygen consumption and anaerobic thresholds are recognized as pivotal factors for time trial cycling performance. ${ }^{6}$ However, in road cycling the majority of the competitions are mass-start races, in which anaerobic reserve, bike handling skills, tactical abilities, and decision making could play an important role.

In this regard, only one study ${ }^{2}$ correlated physiological parameters with overall race outcomes in road cycling. In this study, Menaspà et $\mathrm{al}^{2}$ highlighted the fact that junior Italian cyclists with

Gallo and Filipas equally contributed toward this manuscript. Gallo, Filipas, Garbin, and Codella are with the School of Exercise and Sports Sciences, Università degli Studi di Milano, Milan, Italy. Filipas, Codella, and Lovecchio are with the Dept of Biomedical Sciences for Health, Università degli Studi di Milano, Milan, Italy. Filipas and Codella are also with the Dept of Endocrinology, Nutrition and Metabolic Diseases, IRCCS MultiMedica, Milan, Italy. Tornaghi is with the

a.Pe Laboratorio di valutazioni delle prestazioni, Verano Brianza, Monza and Drianza, Italy. Lovecchio is also with the Laboratory of Adapted Motor Activity (LAMA), The University of Pavia, Pavia, Italy. Zaccaria is with the Centro interdipartimentale di Biologia e Medicina dello Sport, The University of Pavia, the best places in the final annual national ranking were older and with superior aerobic (ie, $\mathrm{VO}_{2} \max$, respiratory compensation point, peak power output) but not anaerobic (5-s maximum power output) characteristics.

To date, it is still unknown whether chronological age, level of biological maturation, anthropometric, and physiological parameters are correlated with race performance in younger age groups and, more generally, if these factors affect performance in under 17 (U17) endurance athletes. Therefore, the purpose of our study was to report the anthropometric and physiological reference values of U17 Italian cyclists and to observe whether these parameters and biological and/or chronological age can be scrutinized as an index of performance or underperformance in this specific age group. Our hypothesis was that chronological age, level of biological maturation, anthropometric, and physiological values are predictors of higher performances in U17 cyclists.

\section{Participants}

A total of 103 male road cyclists aged 15-16 years were recruited for this study. They were part of 4 different Italian teams affiliated with the Italian National Cycling Federation, and competed in the Italian U17 category. The study design and procedures were approved by the University's local ethics committee and followed the ethical principles for medical research involving human participants set by the World Medical Association Declaration of Helsinki. Parents of all the athletes involved in the research project provided written informed consent before the athletes participated in the study.

\section{Design}

Data were collected for 10 consecutive seasons, from 2010 to 2019. Anthropometric characteristics (ie, height, weight, body mass index
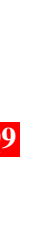
$[\mathrm{BMI}]$ ), physiological (ie, absolute and relative power output values at $2 \mathrm{mmol} / \mathrm{L}$ [Watts at $2 \mathrm{mmol}$ and Watts per kilogram at $2 \mathrm{mmol}$ ] and $4 \mathrm{mmol} / \mathrm{L}$ [Watts at $4 \mathrm{mmol}$ and Watts per kilogram at $4 \mathrm{mmol}$ ]), and maturational (peak height velocity $[\mathrm{PHV}]$ ) characteristics were recorded in season between June and July. The U17 competitive season starts in April and ends in October. In addition, points accumulated in the general national ranking during the year of the test were collected. A study of our research group showed that using points to assess performance outcomes in cycling is a reliable tool. ${ }^{8}$

\section{Procedures}

\section{Q1 I) - ower-Blood Lactate Relationship Assessment}

An incremental ramp test was conducted in a temperature-controlled room with participants performing the test on the frame of their 0 vn bike, fitted on the Cyclus2 ergometer (RBM Cyclus2; RBM uektronik-automation GmbH, Leipzig, Germany). Participants performed 10 minutes of warm-up at $100 \mathrm{~W}$. Thereafter, the power was increased by $30 \mathrm{~W}$ every 4 minutes until voluntary exhaustion.

blood sample was taken from the earlobe for the determination of Q12 Jod lactate at the end of each step (Lactate Plus; Nova Biomedical, ilan, Italy). Pedaling cadence was set between 90 and $100 \mathrm{rpm}$ for

e entire test. Using the Cyclus2 software, the power-lactate polynomial curve was plotted to calculate Watts at $2 \mathrm{mmol}$, Watts per kilogram at $2 \mathrm{mmol}$, Watts at $4 \mathrm{mmol}$, and Watts per kilogram at Q1 14 nmol. ${ }^{9}$ Participants' biological maturation was estimated through .ne formula proposed by Moore at al. ${ }^{10}$ This calculation estimates maturity offset, providing the result in years to or from PHV.

\section{Performance Level}

In order to evaluate the overall performance level, the annual Italian national ranking of Italian National Cycling Federation was used. This ranking assigns 5, 4, 3, 2, and 1 points at each race to the first, second, third, fourth, and fifth places, respectively. This system is the same one used by Menaspà et $\mathrm{al}^{2}$ in a previous study on junior cyclists. For the analysis, participants were divided into 2 subgroups: "unsuccessful" $(n=61)$, which included cyclists who did not score any points during the entire season (ie, they never achieved a top 5 in a race), and "successful" $(n=70)$, including cyclists who scored at least 1 point (ie, they finished at least once in the top 5 in a race). For this age group, race distance is between 40 and $80 \mathrm{~km}$ for a duration that ranges between 1 and 2.5 hours. The riders in our sample rode 34 (4) (30-40) races per year.

\section{Statistical Analyses}

All data are presented as mean (SD). The assumption of normality was checked using the Shapiro-Wilk test. All the data showed normal distribution. Independent samples $t$ tests were conducted for group comparisons of age, body mass, BMI, height, PHV, absolute and relative power output at a blood lactate concentration of $2 \mathrm{mmol} / \mathrm{L}$ and $4 \mathrm{mmol} / \mathrm{L}$. The effect size for each comparison is reported as Hedge $g$ using the small $=0.2$, medium $=0.5$, and large $=0.8$, Cohen ranges. ${ }^{11}$ The data analysis was performed using the SPSS software (version 26.0; SPSS Inc, Chicago, IL).

\section{Results}

The comparisons between successful and unsuccessful riders are reported in Table 1.
Table 1 Comparison Between Successful and Unsuccessful U17 Cyclists

\begin{tabular}{lcccc}
\hline & \multicolumn{3}{c}{$\begin{array}{c}\text { Hedge } g \\
\text { effect } \\
\text { size }\end{array}$} & $\boldsymbol{P}$ \\
\hline Age, y & $\begin{array}{c}\text { Successful } \\
(15.7(0.6)\end{array}$ & $\begin{array}{c}15.5(0.6) \\
(15-16)\end{array}$ & 0.46 & .008 \\
Height, m & $1.75(0.07)$ & $1.74(0.08)$ & 0.15 & .445 \\
& $(1.58-1.88)$ & $(1.58-1.98)$ & & \\
Weight, kg & $62.2(6.5)$ & $61.2(7.5)$ & 0.13 & .382 \\
& $(46-76)$ & $(44-85)$ & & \\
BMI, kg/m & $20.2(1.3)$ & $20.1(1.5)$ & 0.07 & .583 \\
& $(16.7-22.8)$ & $(17.2-23.8)$ & & \\
PHV, y & $1.97(0.62)$ & $1.74(0.59)$ & 0.39 & .028 \\
& $(0.89-3.14)$ & $(0.58-2.69)$ & & \\
Power at & $223(29)$ & $198(28)$ & 0.84 & $<.001$ \\
2 mmol/L, W & $(135-285)$ & $(125-288)$ & & \\
Power at & $260(31)$ & $234(34)$ & 0.79 & $<.001$ \\
4 mmol/L, W & $(182-327)$ & $(147-342)$ & & \\
Power at & $3.59(0.41)$ & $3.26(0.39)$ & 0.85 & $<.001$ \\
2 mmol/L, W/kg & $(2.66-4.50)$ & $(2.31-3.96)$ & & \\
Power at & $4.19(0.44)$ & $3.85(0.40)$ & 0.81 & $<.001$ \\
4 mmol/L, W/kg & $(3.22-5.14)$ & $(2.91-4.55)$ & & \\
\hline
\end{tabular}

Abbreviations: BMI, body max index; PHV, peak height velocity; Power at $2 \mathrm{mmol} / \mathrm{L}$, power output value at $2 \mathrm{mmol} / \mathrm{L}$; Power at $4 \mathrm{mmol} / \mathrm{L}$, power output value at $4 \mathrm{mmol} / \mathrm{L} ; \mathrm{U} 17$, under 17.

No significant differences were found for height, weight, and BMI between successful and unsuccessful riders. Successful riders were older, with advanced biological maturation and significantly higher Watts at $2 \mathrm{mmol}$, Watts per kilogram at $2 \mathrm{mmol}$, Watts at $4 \mathrm{mmol}$, and Watts per kilogram at $4 \mathrm{mmol}$ than their unsuccessful counterparts.

\section{Discussion}

This was the first study reporting anthropometric characteristics, level of biological maturation, and physiological characteristics of competitive national U17 cyclists. Confirming our preliminary hypothesis, the main finding was that higher absolute and relative power outputs at $2 \mathrm{mmol} / \mathrm{L}$ and $4 \mathrm{mmol} / \mathrm{L}$ are largely associated $(P<.001$; effect sizes $=0.79-0.85)$ with success in races of U17 competitive cyclists.

Menaspà et $\mathrm{al}^{2}$ reported similar findings, showing a correlation between superior aerobic characteristics and race results in junior cyclists. This suggests that, even if other factors such as tactics, bike handling skills, decision making, and anaerobic reserve could impact race outcomes, aerobic parameters remain crucial in determining race results in youth road cycling.

Ultimately, the authors could not ascertain whether this was related to genetic or training factors, as endurance training has been shown to reduce blood lactate accumulation at the same exercise intensity, even in a young population. ${ }^{12}$ Furthermore, in youth cycling categories the performance level is very heterogenous. Therefore, it remains to be determined whether these results could be extended or not to more homogeneous performance groups, such as elite athletes. In fact, in professional cyclists a correlation between aerobic characteristics and time trial results has been reported, ${ }^{13}$ while no studies have been conducted on mass-start races or general rankings, in which mass-start race are predominant. 
As to chronological age and PHV, the authors found that successful cyclists were also older and with advanced biological maturation than their unsuccessful counterparts, although no differences in anthropometric characteristics (height, body mass, and BMI) were highlighted. This finding could suggest that success in youth categories is highly dependent on the level of maturation of the athletes, although biological age was only theoretically derived. ${ }^{10}$ In addition, the present study included only Italian U17 cyclists. Future research is needed in multicenter studies with cyclists from different countries.

\section{Practical Applications}

Anthropometric and physiological values of the present study could be useful for coaches in a comparison of their cyclists with successful and unsuccessful cyclists in the U17 category. In particular, absolute and relative power output at specific lactate concentrations seems to be a critical determinant of U17 performance, highlighting the importance of physiological assessments in this specific age group. In addition, the fact that chronological age and biological maturation plays a key role in the race results could induce national cycling federations to split the youth categories on an annual basis. This decision could help young athletes not to lose motivation during the first year in the age category.

\section{Conclusion}

Higher absolute and relative power output at $2 \mathrm{mmol} / \mathrm{L}$ and $4 \mathrm{mmol} / \mathrm{L}$ is largely associated with success in U17 competitive cycling races. Moreover, biological maturation is positively corre-

Iic ted to success in this age category.

\section{Acknowledgments}

The authors thank ASD Pedale Senaghese, ASD Veloclub Sovico, GS Alzate Q1

¿ : anza, UC Costamasnaga for assistance with participant recruitment.

\section{References}

1. Pérez-Landaluce J, Fernández-García B, Rodríguez-Alonso M, et al. Physiological differences and rating of perceived exertion (RPE) in professional, amateur and young cyclists. Sports Med Phys Fitness. 2002;42(4):389-395. PubMed ID: 12391431
2. Menaspà $\mathrm{P}$, Rampinini E, Bosio A, Carlomagno D, Riggio M, Sassi A. Physiological and anthropometric characteristics of junior cyclists of different specialties and performance levels. Scand J Med Sci Sports. 2012;22(3):392-398. PubMed ID: 20807389 doi:10.1111/j. 1600-0838.2010.01168.x

3. Aagaard P, Andersen JL, Bennekou M, et al. Effects of resistance training on endurance capacity and muscle fiber composition in young top-level cyclists. Scand J Med Sci Sports. 2011;21(6): 298-307. PubMed ID: 21362056 doi:10.1111/j.1600-0838.2010. 01283.x

4. Sanders D, Abt G, Hesselink MKC, Myers T, Akubat I. Methods of monitoring training load and their relationships to changes in fitness and performance in competitive road cyclists. Int J Sports Physiol Perform. 2017;12(5):668-675. PubMed ID: 28095061 doi:10.1123/ ijspp.2016-0454

5. Van Schuylenbergh R, Vanden Eynde B, Hespel P. Correlations between lactate and ventilatory thresholds and the maximal lactate steady state in elite cyclists. Int J Sports Med. 2004;25(6):403-408. PubMed ID: 15346226 doi:10.1055/s-2004-819942

6. Atkinson G, Davison R, Jeukendrup A, Passfield L. Science and cycling: current knowledge and future directions for research. J Sports Sci. 2003;21(9):767-787. PubMed ID: 14579871 doi:10. 1080/0264041031000102097

7. Cheung S, Zabala M. Cycling Science. Human Kinetics; 2017.

8. Filipas L, La Torre A, Menaspà $\mathrm{P}$, Giorgi $\mathrm{H}$. Achieving grand tour success: a pilot study using cycling's world tour points. J Sports Med Phys Fitness. 2018;58(10):1432-1438. PubMed ID: 28677943 doi:10.23736/S0022-4707.17.07526-0

9. Heuberger JAAC, Gal P, Stuurman FE, de Muinck Keizer WAS, Mejia Miranda Y, Cohen AF. Repeatability and predictive value of lactate threshold concepts in endurance sports. PLoS One. 2018; 13(11):e0206846. PubMed ID: 30427900 doi:10.1371/journal.pone. 0206846

10. Moore SA, McKay HA, Macdonald H, et al. Enhancing a somatic maturity prediction model. Med Sci Sports Exerc. 2015; 47(8): 17551764. PubMed ID: 25423445 doi:10.1249/MSS.0000000000000588

11. Cohen J. Statistical Power Analysis for the Behavioural Sciences. 2nd ed. Hillsdale, NJ: L. Erlbaum Associates; 1988.

12. Armstrong N, McManus AM, eds. The Elite Young Athlete. Vol. 56. Basel, Switzerland: Karger; 2011:59-83.

13. Lucia A, Hoyos J, Pérez M, Santalla A, Earnest CP, Chicharro JL. Which laboratory variable is related with time trial performance time in the Tour de France? Br J Sports Med. 2004;38(5):636640. PubMed ID: 15388555 doi:10.1136/bjsm.2003.008490 


\section{Queries}

Q1. Please note that titles should generally not be full sentences. Please consider an edit to your title to avoid the full sentence.

Q2. Please check if "Va.Pe Laboratorio di valutazioni delle prestazioni" is correct.

Q3. Please ensure author information is listed correctly here and within the byline.

Q4. Please check whether the changes to the sentence beginning "A total of ..." preserve the intended meaning.

Q5. Please check whether the changes to the sentence beginning "Power associated ..." preserve the intended meaning.

Q6. Would you consider changing "ruled" to "governed" in the sentence beginning "International road cycling ..."?

Q7. Please check whether the change to the sentence beginning "To the best of our knowledge ..." preserves the intended meaning.

Q8. Please check whether the hierarchy of section level headings is correct.

Q9. Please mention the name of the university in the sentence "The study design and ...."

Q10. Please note that there cannot be only one subhead under a level (must be at least 2). Please adjust the headings as needed.

Q11. Please check whether the added information is correct for "RBM Cyclus2." If not, please make changes.

Q12. Please check whether the added information is correct for "Nova Biomedical." If not, please make changes.

Q13. Please provide the expansion of "rpm" in the sentence "Pedaling cadence was set ...."

Q14. Please check whether the changes to the sentence beginning "Using the Cyclus2 software ..." preserve the intended meaning.

Q15. Please provide stub head for column 1 in table 1.

Q16. Please note that "mMol" has been changed to "mmol" in all occurrences.

Q17. Originally, Ref. 11 cited at the end of the sentence beginning with "Ultimately, we could not ..." has been changed to Ref. 12. Please confirm this is correct.

Q18. Please check whether "under 17" should be "under-17" throughout the article.

Q19. Please check whether the changes to the sentence beginning "The authors thank ..." preserve the intended meaning.

Q20. Please provide publisher location for Ref. 7. 